include the more medially placed palaeo-spinothalamic fibres. Its complication is a very high risk of diplopia and it cannot be done bilaterally because of the risk of hearing loss. It is a procedure with limited application and is done only at a few centres where particularly interested surgeons perform it (Nashold et al. 1969).

\section{OPERATIONS ON THE THALAMUS}

Despite more than 20 years of activity in this field, there is little indication that a single operation, or even a multicentric operation in this region, will give pain relief devoid of complications. There is a fairly high risk with a reasonably low level of success. It is as yet no more than experimental surgery, best suited to a limited number of centres and not universally applicable. It is of very little use in the treatment of thalamic pain and for other conditions in which it has been tried. Better methods of treatment are available.

\section{OPERATIONS ON THE FRONTAL LOBE}

There was a time when it was thought that ablation of parts of the frontal lobes would solve the problem of suffering associated with pain. Prefrontal leucotomy interrupts the frontothalamic projection system, and emotional responses are affected more than intensity of pain experience because there is no division of fibre tracts directly responsible for the carrying of impulses concerned with nociception. To be effective, these operations have to be rather extensive and then carry an unacceptable risk of personality disturbance. When they are of smaller format, they fail in their purpose of pain relief. The advent of various psychotropic drugs has made the use of these operations very limited indeed. In some very selected individuals with pain, this type of operation, particularly the very limited operation of cingulotomy, may play a part. A patient with an obsessive compulsive personality who now has the burden of being morbidly preoccupied with his plight could perhaps be helped.

\section{ELECTRICAL STIMULATION}

Electrical stimulation can be effective in controlling pain, even if severe and persistent, although appreciable difficulties and limitations still exist. Effective pain control methods are transcutaneous, percutaneous, peripheral nerve, dorsal column, ventral column, thalamic and internal capsular stimulation. These methods vary in regard to risk, effectiveness in given pain problems, duration of benefits and technical difficulties. The enthusiasm for brain stimulation methods has somewhat decreased almost as rapidly as they have evolved. The technical problems of electrode failure, electrode movement and the variability of human anatomy are measureable defects. The difficulties with patient selection still seem to reign supreme and the success and failure rates run parallel to all other methods of pain treatment. Time is necessary to assess the long-term results of treatment and effects on the brain. It has a limited application in carefully selected patients and this should be done at special centres.

The answer to pain is not surgery. It is doubtful whether the answer will be electrical stimulation because it is based on the same shaky anatomico/physiological assumptions as surgery. The answer will most likely be biochemical and at the as yet nebulous plane of interaction between chemical action and psychological experience.

\section{References}

Abbe, R. (1889): A contribution to surgery of the spine. Med. Rec. N.Y. 35, 149 - 152.

Maher, R. M. (1955): Relief of pain in incurable cancer. Lancet 1, 18 - 20.

Mullan, S., Hekmatpanah, J., Dobben, G. and Beckman, F. (1965): Percutaneous intramedullary cordotomy utilizing the unipolar electrolytic lesion. J. Neurosurg. 22, $548-553$.

Nashold, B. S., Wilson, W. P. and Slaughter, D. G. (1969): Stereotactic mid-brain lesions for central dysaesthesia and phantom pain. J. Neurosurg., 30, $116-$ 126.

Sjöqvist von O. (1937): Eine neue Operationsmethode bei Trigeminusneuralgie durch Schneidung des Tractus Spinalis Trigemini. Zbl. Neurochir. 2, 274-281.

Spiller, W. G. and Martin, E. (1912): The treatment of persistent pain of organic origin in the lower part of the body by division of the anterolateral column of the spinal cord. J. Am. Med. Ass. 58, $1489-1490$.

Sweet, W. H. and Wepsic, J. G. (1974): Controlled thermocoagulation of the Trigeminal ganglion and rootlets for differential destruction of pain fibres. Part I: Trigeminal neuralgia. J. Neurosurg. 40, 143 156.

\title{
THE ATTITUDE OF THE MEDICAL PROFESSION TO CHIROPRACTIC +
}

\author{
J. N. DE KLERK* M.B. Ch.B. (U.C.T.), F.R.C.S. (Edin.)
}

\section{HISTORICAL BACKGROUND}

The philosophy underlying chiropractic was first propounded by Daniel David Palmer in the city of

* Head, Dept of Urology, University of Stellenbosch and Chairman, Federal Council, Medical Association of South Africa.

† Address given to physiotherapists and students as part of Congress and 13th National Council in Cape Town, 27th April 1979.
Davenport, U.S.A., in 1895. Palmer claimed that the secret of all disease had been revealed to him and it was caused by displaced vertebrae which pressed against nerves. "By displacement and pressure, they elongate the pathway of the nerve in a manner similar to that by which an impingement upon a wire of a musical instrument induces it to become taut by displacing it from a direct line. This pressure upon a nerve creates greater tension, increased vibration and consequently an increased amount of heat. Heat alters tissue; altered tissue modifies transmission of impulses; modified impulses cause function to be performed 
abnormally." This "principle" which Palmer claimed to have discovered is still the framework of reference for the modern chiropractice philosophy.

This philosophy is clearly enunciated by $A$. E. Homewood (1973) who states: "The founder of the science of chiropractice appreciated the working of Universal Intelligence (God); the function of Innate Intelligence (Soul, Spirit or Spark of Life) within each, wnich he recognised as a minute segment of Universal; and the fundamental causes of interference to the planned expression of that innate Intelligence in the form of Mental, Chemical and/or Mechanical stresses, which create the structural distortions that interfere with nerve supply and thereby result in altered function to the point of demonstrable cellular change, known as pathology."

In the course of time there were certain modifications in this basic approach but the underlying philosophy remained essentially the same and could be summarised in the five basic principles laid down by the President of the National College of Chiropractic in Chicago, Illinois, Joseph Janse (1975). These basic principles relate to "pure" chiropractice and differ widely from those of more recent origin. They are:

- That a vertebra may become subluxated;

That this subluxation tends to impingement on structures (nerves, bloodvessels and lymphatics) passing through the intervertebral foramina;

- That as a result of this impingement, functioning of the corresponding segment of the spinal cord and its connecting spinal and autonomic nerves are interferred with and conduction of nerve impulses is impaired;

- That as a result thereof, the innervation to certain parts of the organism is abnormally altered and therefore such parts become functionally or organically diseased or predisposed to disease;

- That adjustment of subluxated vertebrae removes the impingement of the structure passing through the intervertebral foramina, thereby restoring to diseased parts their normal innervation and rehabilitating them functionally and organically.

It needs to be pointed out that not only is this socalled "influence" effected from vertebral column to the internal organs, but according to the chiropractor it can work in the reverse direction also. The chiropractor believes unequivocally that the function of the vertebral column may be reflexly affected by a pathologically diseased internal organ. I quote: ". . . morever it is possible that internal organic affections alter by reflex pathways the functioning of the vertebral column as an organ of support and movement; the receptor organs send back an excitation to their point of origin; the internal or external organs, making use of the spinal pathway (cells of Dogeil) (sic!) which may be considered on the one hand as a revealing index of morbid internal processes and on the other hand as an aetiological factor in numerous physio-pathological affections. The pain and disorder being the only signs of a vicious circle which only an attempted physical examination will be able to break." (My italics)

It is clear that the concept of vertebral subluxation is central to the "pure" chiropractic philosophy. Amongst modern chiropractors this concept has led to considerable confusion. Haldeman (1975) states: "The determination of the clinical significance of spinal subluxation has been clouded by the large number of widely varying and in many cases, diametrically opposed opinions on this subject which has often been dogmatically adhered to without adequate investigation. The exact clinical significance remains difficult to determine because of the great diversity in its aetiology, the complex nature of the subluxation and the com- parative lack of research."

In November 1972 a paper on "The radiological manifestation of spinal subluxations" was presented at the Houston Conference of Chiropractors. This proved to be no more than the well recognised signs of degenerative spinal disease (spondylosis) familiar to every practising radiologist, of which you all are well aware, present in the great majority of spinal radiographs done on elderly patients who do not necessarily have symptoms referable to the spine.

This apparent confusion has led to numerous attempts to redefine chiropractic. Joseph Janse in his paper "The history of the development of the chiropractice concept" (1975) gives four different definitions and in no single one of these definitions does he include the concept of subluxation. From this paper it seems that the basis of modern "pure" chiropractice is in fact manipulative therapy and not the correction of vertebral subluxation. This is however not the end of the problem as far as the medical profession is concerned. We must clearly understand that the modern chiropractor believes that he had been trained for and is entitled to function as a primary physician and is in no way prepared to limit his practice to the management of musculo-skeletal infirmities by means of manipulative therapy. He believes that he has the right to practise medicine on the same basis as the orthodox family practitioner, a quite different concept from that which is adhered to by the "pure"' chiropractor. To illustrate the degree to which the chiropractor claims his right as a primary health provider, it would be suitable perhaps at this stage to extract a section of a report by the Royal Commission on Social Security in New Zealand (1972), in which Dr. A. W. S. Thompson from the New Zealand Department of Health cross-examined Mr. W. L. Rheeder of the New Zealand Chiropractic Association:

Dr. Thompson: "If there was a chiropractic benefit (medical scheme) would chiropractors treat children with whooping cough under this scheme?"

Mr. Rheeder: "I can only answer that this is a possibility."

Dr. Thompson: "Take a patient obviously suffering from diabetes. Would you or a reputable chiropractor treat such a patient?"

Mr. Rheeder: "Yes".

Dr. Thompson: "I understand you to say that diabetics you would treat?"

Mr. Rheeder: "Yes".

Dr. Thompson: "By spinal manipulation?"

Mr. Rheeder: "Yes".

Dr. Thompson: "What about high blood pressure?"

Mr. Rheeder: "It depends on its origin, but perhaps your honour, could I ask for your guidance on this particular point. We have discussed several specific disorders that Dr. Thompson is asking me. Are we going through from A - Z?"

The Chairman: 'I don't know what you are, but it seems the doctor was getting into an area which was so different from the impression you gave from your description what your activities were."

It is abundantly clear, if there is to be any question of a chiropractic primary health system, such a system would fall far short of the accepted standards of medical care in South Africa and would only be utilised to provide an easy access to medical practice for people who are incapable of or unwilling to undergo a recognised medical training programme.

This claim to the right to practise as a physician capable of practising at primary health care level is clearly outlined by Edward J. McGinnes, (1977) Chairman of the American Chiropractors Associations, who amongst other things states: "We must be skilled in 
differential diagnosis and be alert to the necessity of referral to specialties when indicated." Similarly the New Zealand Chiropractors Association (1975) states: "A chiropractor learns to become a competent diagnostician so that where surgery or other health treatment is indicated, he may immediately refer such patients." From the foregoing it appears quite obvious that this approach now places the chiropractor in a dilemma: must he in order to qualify as a primary point of entry into the health care system discard his "pure' chiropractic principles, renounce his claim as a member of the "largest drugless healing profession" (Bromley, 1975) and refer his patients to the medically qualified practitioner who is allowed to prescribe these drugs, or must he return to the prcservation of chiropractice in its "pure" form.

The claim of the modern chiropractor that he is sufficiently qualified to practise as a primary health care physician is what concerns me most. There is abundant evidence to show that these chiropractors regard their scope as being much wider than commonly supposed. They train and practise as a primary physician not as a manipulative therapist (The Chiropractic Board New Zealand, 1978), Let us now examine the basis for these claims:

\section{THE CHIROPRACTIC TRAINING PROGRAMME}

The curricula of chiropractic colleges are most revealing. It is safe to say that with the exception of surgical procedures, there is not a single element of medical practice for which the chiropractic colleges do not claim to provide training. Paediatrics, internal medicine, psychiatry and any medical discipline you wish to name, are taught. One can take any Journal of Chiropractic published monthly by the American Chiropractic Association and you will find articles on paediatric infections and viral diseases, digestive problems, respiratory problems, genito-urinary problems, "the mega-vitamin approach to schizophrenia," (sic!!) diabetes mellitus, atherosclerosis and the management of angina pectoris. All of these disciplines are taught despite the fact that the Accrediting Commission of the Department of Health, Education and Welfare of the United States has reported that chiropractic theory and practices are not based upon the body of basic knowledge related to health, disease and health care that has been widely accepted by the scientific community (U.S. Department of Health, 1968). In both, the United States of America and Canada the training which is provided is quite apparently not directed solely towards the manipulative treatment of musculo-skeletal disorders. Major chiropractic schools provide a 4-year course of instruction in two broad categories, viz basic science and chiropractic principles. The basic sciences include anatomy, chemistry, physiology, pathology and microbiology, and chiropractice principles include chiropractic technique and differential diagnosis. According to a report to the Minister of Health of New Zealand (Consumer Review 9, 1976), no evidence could be adduced to show that the teaching of scientific subjects was conducted by qualified personnel.

\section{THE VALIDITY OF CHIROPRACTIC}

The chiropractors have strenuously advocated that they must be regarded as a valid healing art distinct from other medical services. To quote a few sources: "It is the reason why that the science of chiropractic offers that differentiates the practice from that of the medical profession." The American Chiropractic Association states: "(it) strongly supports chiropractic as a separate and distinct healing art." The International
Chiropractic Association states its concern with "the preservations of chiropractic as a separate and distinct health care service." The New Zealand Chiropractic Association states: "The chiropractic profession has developed as a separate and distinct profession in the healing arts due to its adherence to principles which have been rejected by organised medicine. In this context we should note the words of the American Chiropractic Association's President, Stephen E. Owens (1974): "Finally, we are healers in the midst of this extraordinary therapeutic drug culture explosion with its iatrogenic nightmares, surgical promiscuity, hospital horrors and merchants of medicine crying that health can be purchased ..." Thus whilst the "pure" chiropractor denigrates modern medical practice at every opportunity, the modern chiropractor today finds himself increasingly faced with a situation where of necessity he will have to alter his inflexibility with regard to the accepted standards of Western medicine if he wishes to be accepted as a primary health care provider.

This latter concept of the scope of chiropractic is what concerns the bona fide medical practitioner the most. Whereas it might be argued that the activities of chiropractors involved in primary health care can be carefully limited by legislation, this is not the case. The Commission on Chiropractic in South Africa (1962) states: "The principle of chiropractic does not lend itself to restriction and therefore it is not possible to define the scope of his practice or list disorders to which it can be restricted. In other words, conditional recognition of chiropractic is not practicable." This has been borne out clearly by the failure of North American legislators to restrict the scope of chiro. practic.

Although unacceptable by legitimate medical standards, do the chiropractors then provide a specialised service beneficial to patients and the global health service? In Australia the Australian Committee of Enquiry into Chiropractice described the reactions of patients under chiropractic care thus: ". . . almost uniformly there was an extremely high level of satisfaction expressed with the care received and the improvement experienced as a result of treatment." This study indicated that approximately $50 \%$ of patients seeking chiropractic care had previously consulted (other) medical practitioners or chiropractors.

If this is indeed so, it behoves us to investigate by what means this patient satisfaction has been attained. There are various possibilities to consider:

- Is it due to manipulative dexterity and technique? Although it is possible that some of the benefit which is derived from chiropractic care may be due to the actual process of manipulation, however it be described, there is no objective evidence for or against this hypothesis, either from chiropractic or other sources. So it is to be noted that the NINDS Workshop on the Research Aspects of Spinal Manipulative Therapy (Goldstein, 1975) and the staff review and analysis of available data, clearly indicate that specific conclusions could not be derived from scientific literature for or against the practice of spinal manipulative therapy or the pathophysiologic foundation from which it is derived.

Is it possibly a placebo effect? In other words, a method of treatment given more to please than to benefit the patient, in many respects similar to the practice of "laying on of hands."

Is the chiropractor more versed in a proper doctor/ patient relationship? A recent study concluded by the University of Utah College of Medicine (Kanc, et al., 1974) showed that there was no essential 
difference in the outcome of therapy for low backache whether given by a medical practitioner or a chiropractor but that the patient of the chiropractor was more satisfied with the degrete to which he was made to feel welcome. The authors of this study stressed the implications of these reactions. "On the basis of our study and others, it appears the chiropractor may be more attuned to the total needs of the patient than his medical counterpart. The chiropractor does not seem hurried, he uses language patients can understand, he gives them sympathy and he is patient with them, he does not take a superior attitude towards them. In summary, it is an intimate relationship rather than a superiorordinate/ subordinate relationship." The chiropractor has developed the art of self-projection which he astutely applies at patient as well as all other levels.

(b) Are those cases which appear to benefit not merely cases of spontaneous remission? The modern chiropractor considers himself competent to treat a wide range of illnesses but the majority of patients appear to consult him more for musculo-skeletal disorders than other illnesses. It is recognised that the majority of musculo-skeletal disorders do show a strong tendency towards self-limitation, whether the patient receives treatment or not. In many cases there are periods, often long. of spontaneous remission. For example, you all know that the symptoms of lumbar degeneration are classically episodic. The efficacy of any form of treatment of musculoskeletal disorders is therefore notoriously difficult to assess and it remains a matter of speculation whether the clinical improvement claimed for chiropractic care in a given case is due to the coincidence of spontaneous remission. In all probability the truth lies somewhere in the middle of all these factors. Whatever the reason, the fact is still quite clear - nothing which the chiropractor does cannot be equally well performed by the medical practitioner and/or the physiotherapist.

\section{THE RISK OF CHIROPRACTIC}

It may be argued that provided the patient is satisfied and is relieved of his symptoms, it doesn't really matter whether he goes to a medical practitioner or to a chiropractor. This may be a reasonable assumption provided that there is no risk attached to chiropractic treatment, and his methods of treatment are not noxious las far as the patient is concerned. The principle risk of chiropractic lies in the fallacious philosophy that all disease is amenable to treatment by manipulative therapy. Thus the treatment of infectious diseases (such as whooping cough), the treatment of severe systemic diseases such as diabetes mellitus, essential hypertension and such like conditions, by means of chiropractic manipulation, serves to delay the proper management of serious life-threatening conditions. In this respect therefore there is a very real risk attached to chiropractic treatment. Spinal manipulation is no substitute for ganglion blockers in the treatment of hypertension, endocrine therapy in disseminated cancer of the prostate, insulin in the treatment of diabetes, immunisation in the prevention of whooping cough, or antibiotics in the treatment of the complications of whooping cough. This risk is nowhere more apparent than in the case of sick children. This was clearly recognized by a report issued in 1972 by the Montreal Children's Hospital. "By calling himself "doctor", by taking $X$ rays, by pretending to be qualified. the chiropractor creates a false image as to his ability to deal with paediatric problems. This leads directly to the delay in proper diagnosis being made and the correct therapy being started which might affect the child for the rest of his life." Similarly in 1975 the United States Consumers Union (Consumer Reports, 1975) recommended the following: ". . . the Consumer Union believes that chiropractic is a significant hazard to many patients. Above all, we would urge that the chiropractors be prohibited from treating children. Children do not have the freedom to reject unscientific therapy that their parents may mistakenly turn to in a crisis". For "children" you can also substitute the unsophisticated patient in our community, the old and weary geriatric patient who has lost his ability to clearly distinguish fact from fiction, and the emotionally unstable who readily fall prey to the sales patter and denigratory activities of the chiropractor. Nowhere is this better illustrated than in their use of radiology!

Manv of us who have been in practice in this country are appalled by the unbridled use of radiological equipment by chiropractors and the highly questionable diagnostic methods which are used to describe fancied spinal displacements and subluxations. I quote from a report from the New Zealand Chiropractic Board (Howe, 1974): "X-ray photography is of special importance because of its ability to depict for the chiropractor the functional abnormalities (my italics) of the spinal column in addition to the various pathological alterations which may occur in the osseous or soft tissues of the body. . . Alterations of spinal alignment in function are frequently well depicted by the use of both static and stress radjography."

This reliance on interpretations which at best are open to serious diagnostic deficiencies speaks for itself. More recently these people have commenced doing extensive pathological laboratory studies. This is something which our Medical and Dental Council does not allow a practitioner to do unless adequate specialised training has been undergone. The chiropractor draws blood with impunity, performs these laboratory tests and creates the spurious public image of an ability to interpret and treat biochemical disturbances due to disease.

\section{POLITICAL ACTIVITY}

In the U.S.A. (and in the R.S.A.) these people have an extensive political lobby. Their freedom of professional activity is the result of this extensive political action. A chiropractor is a political realist and chropractic organisations in this country are making determined efforts to achieve the goal of recognition as an independent primary medical care profession so as to legitimise payment by the medical aid schemes. How this particular action has been mounted in the U.S.A. has been very succinctly expressed by one W. D. Harper, (1974) at that time President of the Texas Chiropractic College, who stated: ". . . with the insidious trend towards socialised medicine in this country (U.S.A.) even though it has or is failing in others, we must prepare ourselves to be part of a team of health providers... . and be primary care physicians of the future if we are going to get a piece of action." (my italics)

The role of politics in the functioning of the chiropractic lobby is well described in a special consumer report published by the Consumers Union of the U.S.A. Inc. as recently as October 1975: ": . . Chiropractors today enjoy a wider range in their scope of practice than any other health practitioner, except a physician. By comparison, other independent health care providers must practise within far stricter limits. A dentist does not treat stomach ulcers, a psychologis doesn't order medication for heart conditions, an optometrist does not treat epilepsy, but chiropractors may 
often do all three and they are permitted to offer treatment in specialities ranging from paediatrics to psychiatry without having the scientific training in one of them. Chiropractic has won that freedom (without engaging in research or demonstrating professional capacity in these fields) by one method alone - political action. For years, grass roots politics has been the life blood of chiropractic. By massing the support of chiropractic patients, the profession has often achieved an effective political voice in legislation affecting its chiropractic services and that voice has been its protection against science. Opponents of chiropractors come to legislative hearings with information, with scientific studies and with the official endorsement of national organisations. Chiropractic comes armed with votes."

Readers may well be aware that a somewhat similar situation occurred in South Africa with the Commission of Enquiry into the Practice of Chiropractic instituted by the Government in October 1962. At present every possible avenue is continually explored to promote their interests at social and political level. Health farms are readily available to politicians and their wives, every opportunity to speak to parliamentary groups is taken - now an attempt is even being made under the guise of involvement with the Health Year to address schools and social clubs!

\section{TO SUMMARISE}

Modern chiropractic quite apparently encourages persons with limited qualifications to practise medicine under another name. The training programme of the modern chiropractor is geared to the role of a primary physician, and not as a manipulative therapist. The restriction of the chiropractor to manipulative therapy alone is not practicable as long as the chiropractor is allowed to project himself to the public at large as a primary physician. There is quite apparently no depth of training in diagnostic methods, and the essential skill of the physician is lacking in every aspect of medical therapy with the possible exception of the management of minor musculo-skeletal ailments. Today modern chiropractic training differs markedly from that given in medical schools, by virtue of its poor quality and the singular emphasis which is placed upon chiropractic - spinal adjustment.

Although many patients swear by chiropractors and state that they receive great benefits from their treatment, the opposite is indeed also true. The cases of serious, life-threatening disease which are allowed to progress under this type of management are common knowledge amongst the medical profession. Available scientific evidence suggests that the benefits apparently derived, if indeed true, are largely due to the transference of confidence from chiropractor to patient; the sharing of faith in manipulation as a form of therapy; the placebo effect of the laying on of hands and the fact that the minor musculo-skeletal disorders which fall into the province of chiropractic are themselves self-limiting or subject to spontaneous remission.

Modern chiropractic is not a healing art, separate and distinct from legitimate medical and paramedical disciplines. It is not based on sound scientific and educational factors and there is little evidence to suggest that it can make a contribution to the health services of South Africa and in particular at primary health care level. There is nothing that the chiropractor can provide that cannot be more than adequately provided for by the legitimate medical and paramedical services. The preservation of this form of thinly disguised quackery is a serious reflection on the standard of medical care which we profess to uphold in South Africa.

\section{Bibliography}

Bromley, W. H. (1975): What's right with the A.C.A.! The A.C.A Journal of Chiropractic, 12, 11 (June).

Consumer Reports, Chiropractors: Healers or Quacks? Consumers Union U.S.A. (Inc.) 1975.

Consumer Review 9. Chiropractic, Fact or Fiction? Consumers Institute of New Zealand, 1976.

Goldstein, M. (1975): The research status of spinal manipulative therapy. The introduction, summary and analysis. U.S.A. Dept. of Health, Education and Welfare Publ no. NIH 76 - 998.

Haldeman, S. (1975): The patho-physiology of the spinal subluxation. Journal of C.C.A., 19, 5 (September). (

Hannan, The Honourable J. R., New Zealand Parliamentary Debates, Oct. $1960325,3362$.

Harper, W. D. (1974): Anything can cause anything. Seabrook Texas.

Homewood, A. E. (1973): The Neurodynamics of vertebral subluxation. Chiropractic Publishers, Canada (page 80).

Howe, J. (1974): Röntgenology in chiropractic. State of the art, 1974. A.C.A. Journal of Chiropractic, 8, 526 (May).

Howe, J. W. (1976): A contemporary perspective on chiropractic and the concept of subluxation. The A.C.A. Journal of chiropractic, X/S 165.

Janse, J. (1975): History of the Development of Chiropractic Concepts. Chiropractic Terminology. U.S Department of Health, Education and Welfare, Publication no. NIH 76 - 998 .

Kane, R. L., Leymaster, C., Ohlson, D., Wolley, F. R., Fischer, F. D. (1974): Manipulating the patient. Lancet, 1, 1333.

McGinnes, E. J. (1977): The number one priority. The A.C.A. Journal of Chiropractic, 14, 13 (February).

Memoire presented on behalf of the St. Justine's Hospital and the Montreal Children's Hospital to the Parliamentary Commission on Bill 269 (Chirop.) February 1972.

Owens, S. E. (1974): Referral. Would you go to you? The A.C.A. Journal of Chiropractic, 11, 10 (April).

Report of the Royal Commission of Enquiry into Social Security in New Zealand, transcript of proceedings, Thursday 15-10-70.

The Australian Commission of Enquiry into Chiropractic.

The Chiropractic Board New Zealand 1978, The Logan College of Chiropractics $1977 / 8$ catalogue, The National College of Chiropractic Bulletin of Information $1977 / 8$

The New Zealand Chiropractors Association (Inc.) The chiropractor in New Zealand, 1975.

U.S. Department of Health, Education and Welfare, Independent practitioners study. Washington, DC: Government Printing Offices, 1968.

\section{RESOLUTION REGARDING PUBLICITY PASSED AT 13TH COUNCIL MEETING}

"THAT the Incoming N.E.C. in the interest of the public image of physiotherapy remind members of its policy j.e. that Physiotherapists who are interviewed by the public media etc must request the permission of N.E.C. or in retrospect of an interview inform the National Executive Committee of the proceedings and that the N.E.C. exert careful discretion when such applications are received." 